\title{
Deformation of the rock pillar caused by bed operation using the room and pillar system
}

\author{
Wiesław Grzebyk ${ }^{1}$, and Lech Stolecki ${ }^{1 *}$ \\ ${ }^{1}$ KGHM Cuprum Ltd Research and Development Centre, 53-659 Wroclaw, Poland
}

\begin{abstract}
The copper ore deposit of the Legnica-Głogów Copper Mining District a one-deck bed formed from the contact of weak sandstone rocks, and solid, durable dolomite rocks, separated by a layer of copper slate. The bed operation is carried out using the room and pillar system. The course of deformation in such bed operation systems is determined by the mutual interaction of particular elements of the geo-mechanical system which include: the roof slab, the pillars and the excavation bed. Due to the possibility of human intervention, structural pillars - whose strength properties can be determined by the appropriate selection of their dimensions and shape - play a particular role in this system. The optimization of the properties of these pillars is mainly based on the results of laboratory tests of rock samples in the strength test machine and on the basis of visual observations of their behavior in situ. The article presents the experimental results carried out under pit conditions in order to determine the rock pillar reaction. Suitable observations were made using the so-called volumetric method. The obtained results were discussed in relation to the results of strength tests on rock samples, indicating the limited similarity to the deformation characteristics.
\end{abstract}

\section{Introduction}

One of the basic geomechanical problems in room and pillar systems of bed operation is the selection of the appropriate dimensions for structural pillars. At the Legnica-Głogów Copper Mining District's copper ore beds, the selection of these dimensions is conditioned by two factors: the guarantee that pillars will provide adequate support for the floor layers and leading the pillars to the subcritical state [1]. Due to technological considerations associated with the provision of the bed, many pillars in their original form have large dimensions, far exceeding the dimensions of the operating pillars at the front of the extraction works.

Generally, the actual operation of the structural pillars subjected to operating pressure is described by determining the deformation-to-strain characteristics obtained from laboratory measurements on rock samples [2-6]. The main research problem consists in demonstrating the consistency of the obtained results of the laboratory tests in this field with the actual deformation characteristics of pillars in mining conditions. The results of this study attempt to answer the above question.

\footnotetext{
*Corresponding author: 1stolecki@cuprum.wroc.pl
} 


\section{Strength characteristics of rock samples in pre- and post- critical conditions}

The equivalent of the structural pillar deformation process in the room and pillar operating system is usually the full deformation-to-strain characteristics of the rock sample obtained under uniaxial compression conditions. Thus, the obtained graph of linear strength for fragile rock samples always contains its ascending, peak and descending sections, which correspond respectively to the pre-destructive condition, the moment of destruction, and the postdestructive state of the rock. The mechanism of destruction for a fragile rock, in the context of linear and volumetric deformations, was provided by Bieniawski [2].

The results of laboratory tests that are carried out on rock samples with normalized shapes and dimensions and the loading rate (ISRM recommendation, Ulusey, Hudson, eds. 2007) mainly show a comparative advantage. On the other hand, the results of strength tests on samples of different dimensions and different load rates, i.e. parameters approximating the real conditions, are more useful for practical purposes. An exemplary effect of changing these parameters based on the mechanical characteristics is shown in Figures 1a and 1b. According to the results of these studies on sandstone samples, "the increase in deformation speed of the rock model results in an increase of its strength and rigidity in the pre-critical state and an increase of the rigidity module in the post-critical state, while the change of the geometry and dimensions of the model in the direction of its length increase relative to its height results in a decrease in the post-critical rigidity [7]."

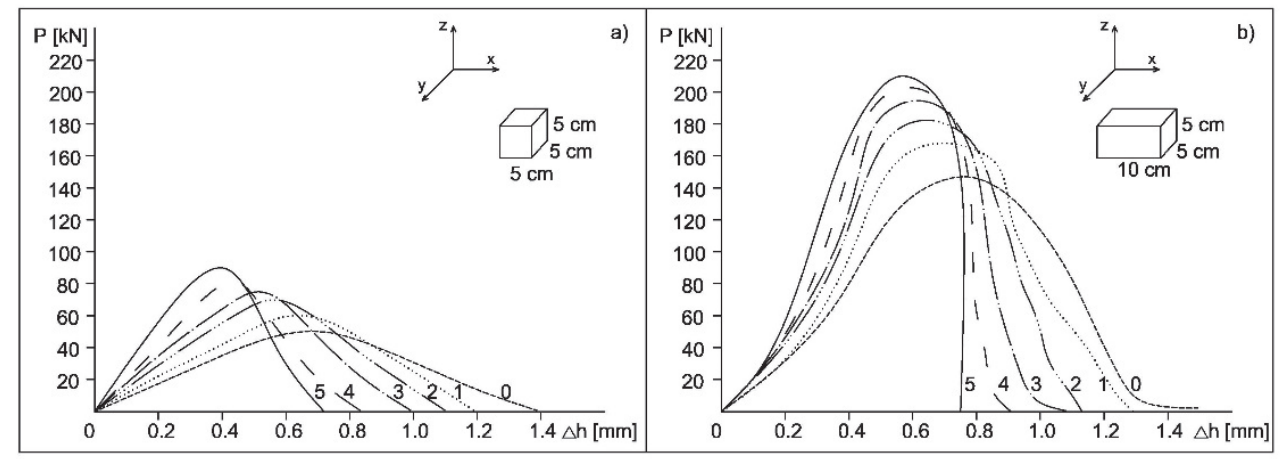

Fig. 1. Mechanical characteristics of square (a) and rectangular (b) models of clay sandstone for different load ing rates: $0-1,1-10,2-102,3-103,4-104,5-105 \mu \mathrm{m} / \mathrm{s}$ (acc. to [7]).

\section{Object-oriented research in situ}

Recognition of the reaction of a pillar-type rock medium under the influence of increasing operating pressure was carried out in one of the operating areas of the copper ore beds of the Legnica-Głogów Copper Mining District. The bed lies at a depth of approx. $300 \mathrm{~m}$ to approx. $1300 \mathrm{~m}$ and is formed as a flat deck with a slight angle in the NW direction. The bed is in contact with solid and durable carbonate rocks (in the upper part) and much weaker sandstone rocks of Rotliegend, separated by a thin layer of copper slate. Operation of the bed is carried out in the one-stage room and pillar system with floor slab deflection.

Relevant tests were performed for the selected pillar positioned ahead of the operating front (Figs. 2, 3). The pillar has a triangular shape measuring $40 \times 32 \times 32 \mathrm{~m}$ and a height of approx. $4 \mathrm{~m}$. 


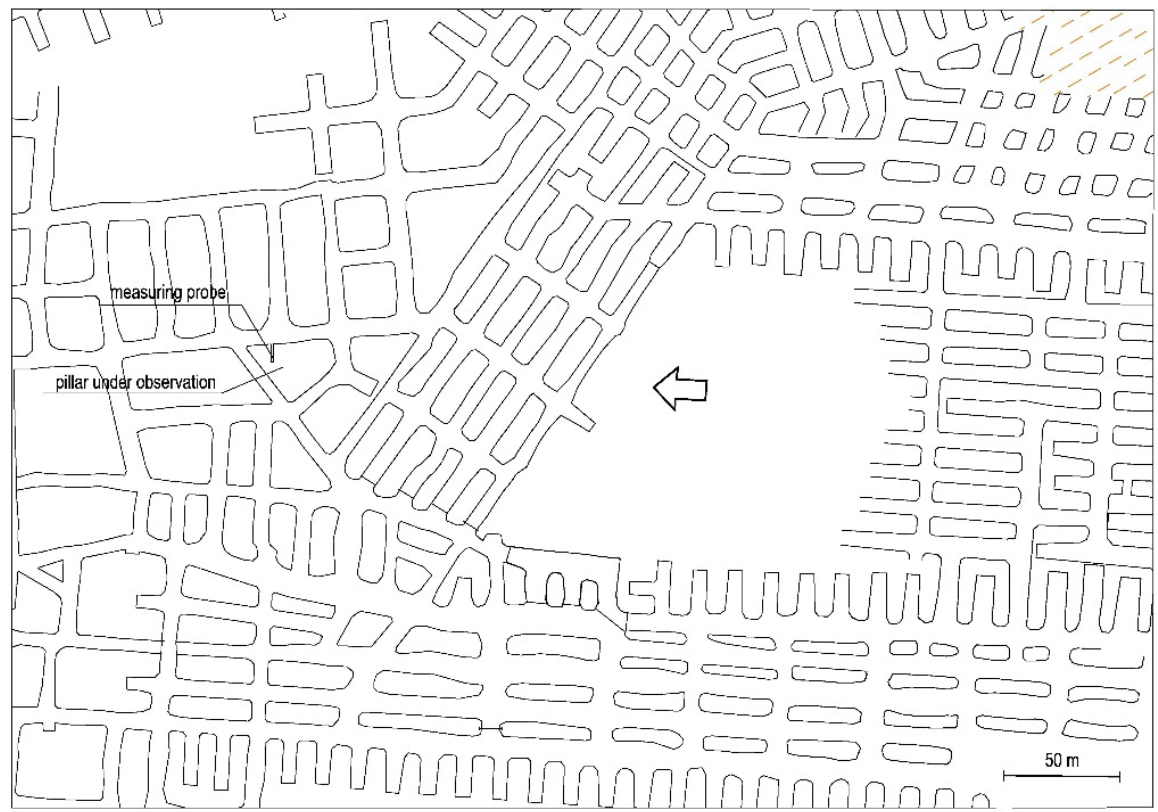

Fig. 2. Mining situation at the start of observation.

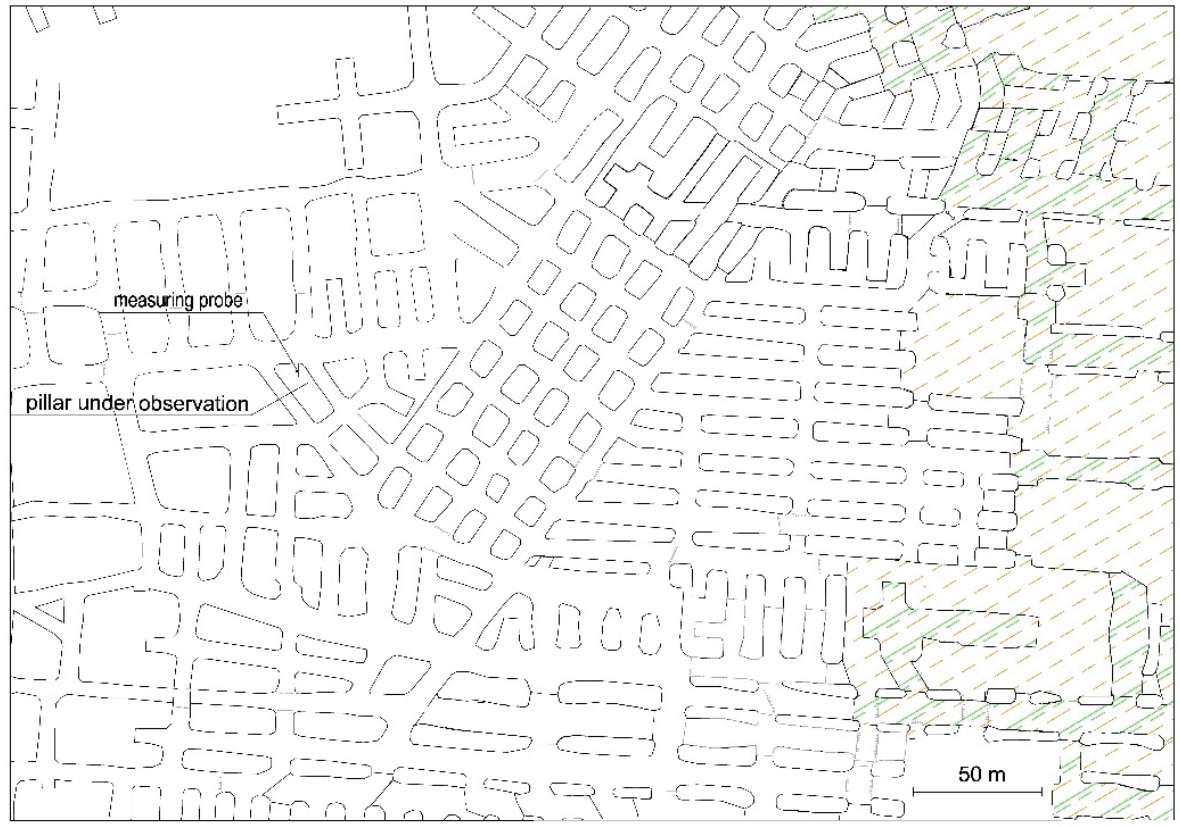

Fig. 3. Mining situation at the end of observation.

In order to determine the deformation characteristics of the pillar, the so-called volumetric measurement method [8] was used. To do this, special measuring probes were inserted into two horizontal holes in the sandstone and dolomite pillar sections; the basic elements of these probes are resilient cylindrical shaped vessels. After inserting the probes to a certain depth in the openings, pressurized hydraulic oil was introduced into the vessels, causing them to expand sideways and close contact against the wall of the hole. The construction of the probe 
prevented the tank from deforming along the axis of the hole. Location of research holes in the pillar in the horizontal projection is shown in Figs 2 and 3, whereas diagram of the measuring system in the vertical projection in Fig. 4. Pipes were routed from the probes, outwards from the boreholes, and connected to the absolute pressure sensors. Changes in oil pressure made at set time intervals were measured.

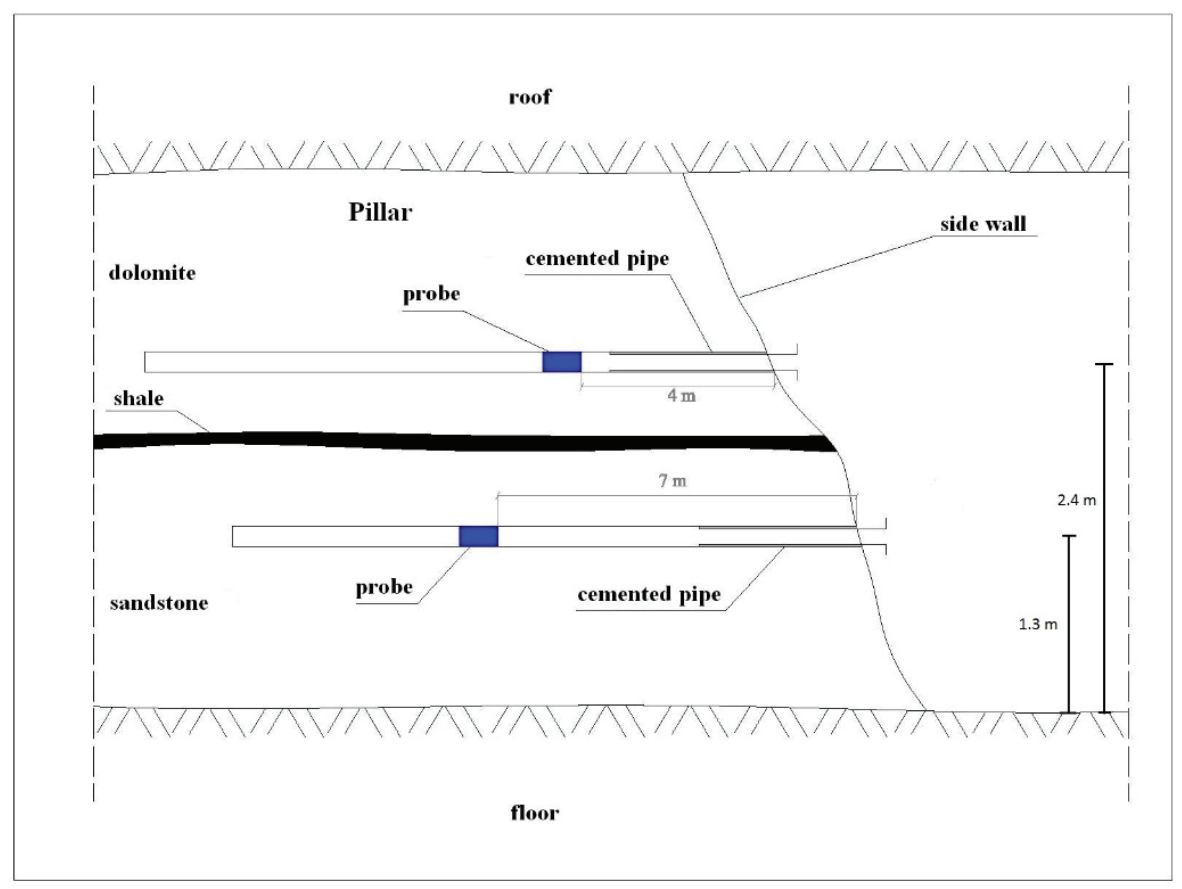

Fig. 4. Diagram of the measuring system in the vertical projection.

\section{Measurement results}

The described measurements were conducted over a period of 14 months. At the time of start of theirs, the operating front was approximately $240 \mathrm{~m}$ from the measuring station and over time, with relatively constant speed (approx. $6.31 \mu \mathrm{m} / \mathrm{s}$ ) it approached the pillar. In the final stage of the measurements, the pillar was cut by creating a working in it, maintaining the efficiency of the measuring system. Measurements were completed when the operating front was approx. $12 \mathrm{~m}$ behind the pillar.

The obtained results of the observations in the form of graphs of pressure changes measured in the sandstone and dolomite parts of the pillar and the progress of the operating front are shown in Figure 5. The time axis, in such an assumed coordinate system, should be regarded as a progressive increase in the load on the pillar of the overlying layers. The reduction of the maximum pressure values until January 2013 was caused by the use of a pressure sensor with a lower measuring range (up to $10 \mathrm{MPa}$ ) at that time.

The graphs show the completely different behavior of solid and durable dolomite rocks as compared to the relatively weak sandstone rocks. Although the pressure changes in the probe vessel placed in sandstone are in the range of up to approx. 7,300 $\mathrm{hPa}$, in the dolomites they do not exceed approx. $560 \mathrm{hPa}$. However, the similarity of pressure in probes on both rock mediums in terms of medium and short-term changes should be emphasized. 
Definitely more susceptible to loading, the sandstone section of the pillar is characterized by several long-term trends in changes depicted in Figure 5 as subsequent phases of pillar structure destruction occurred. After the initial period of pressure drop (phase I), its longterm increase (phase II) was reached, culminating at approximately 9,200 $\mathrm{hPa}$ (maximum I) followed by a decisive drop (phase III) of approx. 5,500 hPa. A further period of rapid pressure increase (phase IV) occurred when the operating front was approx. $20 \mathrm{~m}$ from the measuring station and reached its culmination during the pillar cleavage (peak II). Phases V and VI are, respectively, the decrease and increase of pressure in the separated section of the pillar after passing the operating front.

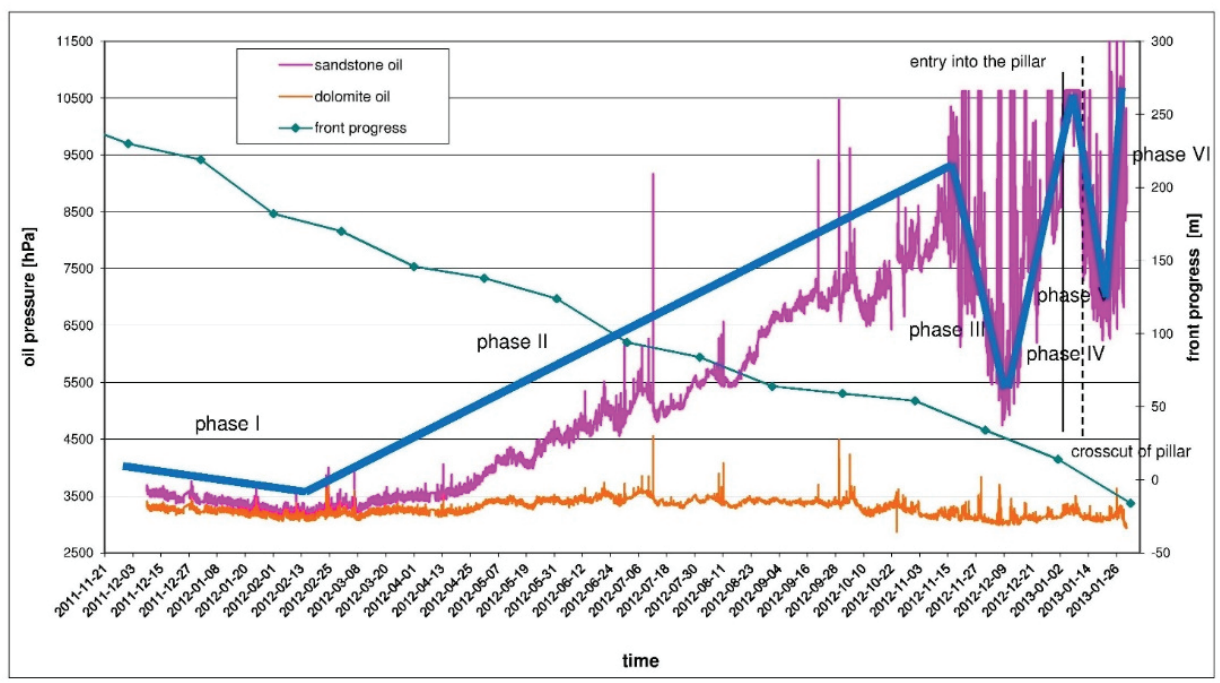

Fig. 5. Graphs of oil pressure variations measured in probe placed in the sandstone and dolomite pillar sections in relation to front progress.

Pressure changes occurring in the dolomitic pillar are discussed in the modified graphs obtained from their average (moving average, $\mathrm{n}=50$ ) and the stretched ordinate corresponding to the pressure in the dolomite medium (Figure 6). After this time period (from $11 / 2011$ to $11 / 2012$ ), the high compatibility of the pressure changes in the sandstone and dolomite mediums, in the dolomite section of the pillar, tended to decrease, with a minimum convergence for the sandstone section of the pillar. This decline temporarily precedes the occurrence of peak I for the sandstone medium and is roughly equivalent to the third phase of destruction of this medium. Visual observations did not show the visible destruction of this section of the pillar during this period.

A detailed analysis of the variability of recorded pressure indicates that both the longterm and the medium-term trends are mainly the effects of short-term pressure pulses, successively. These pulses have different amplitudes and durations. They map the continuous process of destroying the structure of the rock medium, clearly indicating its sequential character. This is expressed in the form of medium-term pressure (temporary waveform) changes and the long-term trend. 


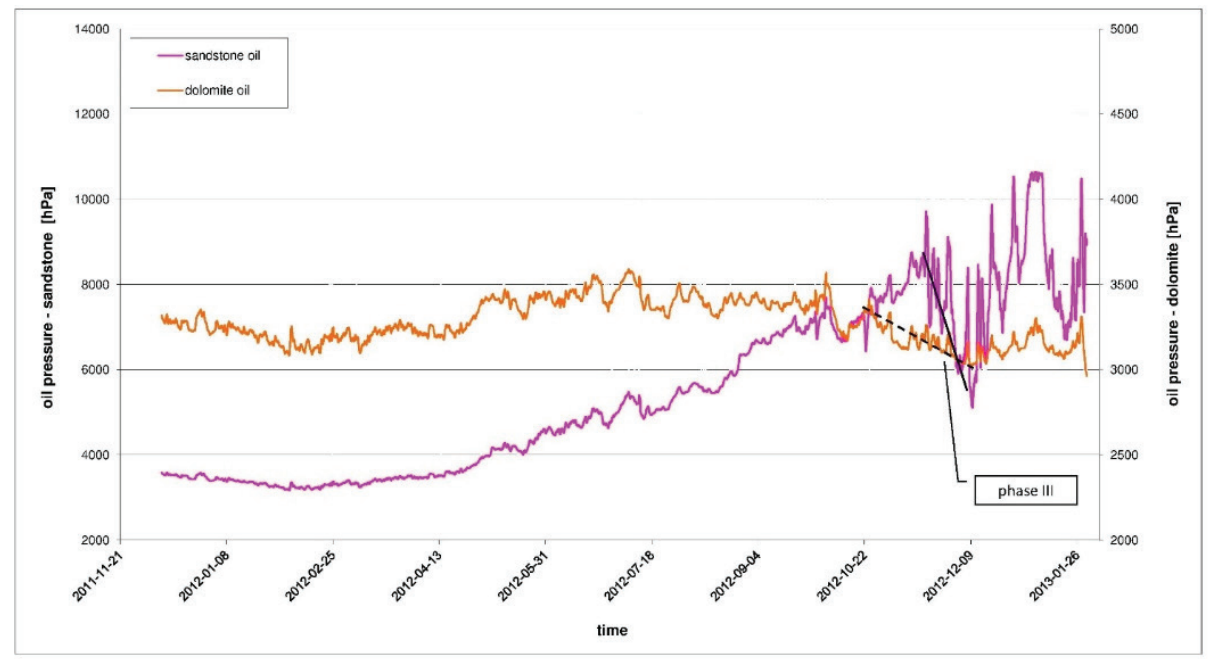

Fig. 6. Smoothed graphs of pressure changes of probe measured in the dolomite and sandstone pillar sections with the marking of the phase III of deformation.

\section{Comparative analysis of the test results on rock samples and in situ conditions}

The comparison of the destruction of the rock medium obtained from rock samples and actual pillar operating conditions indicates the limited similarity of their strength characteristics. In the case of the sandstone pillar sections, the compatibility of these characteristics concerns the presence of phases I and II, peak I and phase III, which must be interpreted successively as: the pre-critical condition, the moment of destruction and the post-critical condition. The fundamental difference between the analyzed objects concerns the presence of a further phase of pillar deformation with the appearance of the subsequent phases, in particular phase IV.

The presence of this phase may indicate the destruction of the pillar structure and the occurrence of the so-called strengthening the structure of the rock medium effect as a result of the reconsolidation process. Phase IV of pillar structure destruction does not occur in the case of rock samples because they are already completely destroyed. The further deformation stage (peak II, phases V and VI) is a consequence of the weakening of the pillar structure as a result of its cleavage. Earlier in relation to the sandstone medium, the third phase of deformation in the dolomite pillar reveals the material properties of this medium and its deformation. Assuming the main forces in the vertical direction and the nature of the influence of these forces on the probe, the observed drop of pressure in the probe placed in the dolomite can only be due to the reduction of lateral pressure exerted on the probe. This is probably indicative of permanent deformations of the dolomitic medium in that direction, i.e. perpendicular to the pillar. These changes are closely correlated with the response to the loading of the sandstone section of the pillar and the vulnerability of the sandstone rock mass in this area, i.e. the medium with significantly weaker strength parameters.

The second significant difference in the strength characteristics of the rock samples and the actual pillar consists in detailing the variation in the measured pressure for the pillar. Unlike a generally smooth curve describing the behavior of a rock sample subjected to a constant loading rate, a very irregular course is observed for the actual pillar in the form of the aforementioned short- and medium-term changes. The most probable source of shortterm pulse pressure variations is the wide range of displacement in elemental volumes of the rock medium, ranging from rock micro-defects to large cracks. On the other hand, medium- 
term pressure changes should be related to temporal and local consolidation of the structure of the rock medium.

The variability of the deformation characteristics of the rock samples and the actual pillars is the result of unfavorable test conditions. It should be assumed that the most important factors that determine this are the size and proportion of the rock sample dimensions and the loading rate in the strength test machine.

\section{Conclusion}

The article presents the experimental results carried out under pit conditions i order to determine the rock pillar reaction to the increasing rock mass. Knowledge of the actual deformation characteristics of the structural pillars in room and pillar operating systems is of paramount importance in the course of selecting the optimum dimensions of these pillars and their response to the operation of the bed [9-11]. So far, the process of deformation of the pillars has been presented from the results of laboratory measurements on rock samples, indicating their pre-critical state, the moment of destruction and the post-critical state (postdestructive). With respect to the actual conditions for larger pillars, the moment of complete destruction of the sample corresponded to the first peak in the pressure gradient measured in the sandstone part of the pillar. According to this comparison, it should be considered that the pillar has already reached residual resilience and should not pose a threat as a result of its sudden destruction. In practice, the pillar structure is reclassified and its strength increases. In the case described above, this situation occurred when the front line was aligned with the pillar in question.

No reconsolidation effect in rock sample studies is probably due to the very small size of the sample. Therefore, in order to better represent the real working conditions of the pillars in the room and the pillar operating system, it seems reasonable to extend the strength tests to larger rock samples and to reduce the proportion of their slenderness to transverse dimensions [12]. In identifying the actual working conditions of the structural pillars should consider in the greater complexity of the models studied in the strength test machine.

\section{References}

1. J. Butra, Eksploatacja złoża rud miedzi w warunkach zagrożenia tapaniami $i$ zawałami (Wydawnictwo KGHM Cuprum, Wrocław, 2010)

2. Z. Bieniawski, Int. J. Rock. Fract. Mech. 4, 4, 415-430 (1968) doi 10.1007/BF00186807

3. W.R. Wawersik, C. Fairhurst, A study of brittle rock fracture in laboratory compression experiments, Int. J. Rock. Mech. Min. 7, 5, 561-575 (1970)

4. A. Nur, J. D. Byerlee, J. Geophys. Res. 76, 6414-6419 (1971) doi 10.1029/JB076i026p06414

5. M. Kwaśniewski, Dylatancja jako zwiastun zniszczenia skaty. Część I. Fizykalna istota zjawiska, Przegląd Górniczy 2, 42-49 (1986)

6. J. Lis, P. Kijewski, Badania własności wytrzymałościowych i odkształceniowych skat z kopalń LGOM $w$ trójosiowym stanie naprężeń, Czasopismo Naukowo-Techniczne Cuprum 4, 17-40 (2007)

7. J. Lis, P. Kijewski, Wpływ prędkości deformacji modeli skalnych na ich zachowanie w stanach przed i pozniszczeniowych, Zeszyty Naukowe AGH, seria Górnictwo 129, 191197 (1987) 
8. W. Grzebyk, L. Stolecki, Pomiary zmian objętościowych masywu skalnego jako wskaźnik oceny stanu górotworu, Materiały Konferencyjne: Górnicze Zagrożenia Naturalne, Katowice, Poland (2013)

9. R. K. Zipf, Toward pillar design to prevent collapse of room-pillar mines, Proc. of 108th Annual Exhibit, Society for Mining, Metallurgy and Exploration Conference SME (2011)

10. C. D. Martin, W. G. Maybee, The strength of hard-rock pillars, Int. J. Rock. Mech. Min. 37, 1239-1246 (2000)

11. G.S. Esterhuzien, D.R. Dolina, J. L. Ellenberger, Pillar strength in underground stone mines in the United Stated, Int. J. Rock. Mech. Min. 48, 42-50 (2011)

12. W.J. Darlington, G.R. Pathegama, S. K. Choi, Rock. Mech. Rock. Eng. 44, 513-529 (2011) doi 10.1007/s00603-011-0161-6 